\title{
As propostas do Setor Educacional do Mercosul para o ensino de História*
}

\author{
Proposals of Mercosur's Education Sector for \\ teaching History
}

\section{Propuestas del Sector Educativo del Mercosur para la enseñanza de Historia}

\author{
Léia Adriana da Silva Santiago* \\ Serlei Maria Fischer Ranzi ${ }^{* * *}$
}

\begin{abstract}
Resumo: O artigo resulta de pesquisa desenvolvida sobre os conteúdos referentes à América Latina no ensino de História. Nesta pesquisa, foram analisados os documentos do Mercosul Educacional, especificamente dos seminários do ensino de História e Geografia, com o objetivo de apresentar as reflexões, as perspectivas e as ações colocadas pelos especialistas para o ensino de História na Educação Básica dos Estados-partes. O artigo conclui sinalizando que a necessidade de integração social e cultural possibilitou a criação do SEM e, posteriormente, a formação do grupo de trabalho no ensino de História e Geografia, cuja preocupação foi incorporar conteúdos curriculares mínimos de História de cada um dos países signatários e discutir sobre um ensino de História que veiculasse abordagens comparativas, que possibilitasse a identificação de traços de identidade comuns e que contemplasse a integração social e o direito à diferença.

Palavras-chave: Ensino de História. Grupo de trabalho. Setor Educacional do Mercosul.
\end{abstract}

\begin{abstract}
This paper results of a research conducted on contents related to Latin America in the teaching of History. In this study we analyzed documents of Mercosur's Educational Sector, specifically, the seminars of History and Geography teaching, with the aim of showing reflections, perspectives and actions raised by experts for the teaching of History in the Basic Education of all States. The article concludes showing that the need for social and cultural integration enabled the creation of the SEM and, later, the creation of the working group in the teaching History and Geography, with a concern for the incorporation of a minimum curriculum of History from each participant country and discuss about a History teaching that is able to show

\footnotetext{
* Este trabalho faz parte da tese defendida no Programa de Pós-Graduação da Universidade Federal do Paraná, orientada pela professora Serlei Maria Fischer Ranzi.

** Docente do Instituto Federal de Ciência e Tecnologia de Goiás. E-mail: <leiasantiago@yahoo.com.br>

*** Docente da Universidade Federal do Paraná. E-mail: <serleif@gmail.com>
} 
comparative approaches, enabling the identification of common traits of identity and addressing social integration and the right to difference.

Keywords: History Teaching. Workgroup. Mercosur's Educational Sector.

Resumen: Este artículo es lo resultado de una investigación llevada a cabo sobre los contenidos relacionados con América Latina en la enseñanza de Historia. En este estudio se analizaron los documentos del Sector Educativo del Mercosur, en concreto los seminarios de enseñanza de Historia y Geografía, con el objetivo de mostrar reflexiones, perspectivas y acciones planteadas por los expertos en enseñanza de Historia en la educación básica de todos los Estados-miembros. El artículo concluye mostrando que la necesidad de integración social y cultural permitió la creación de la SEM y, más tarde, la creación del grupo de trabajo en enseñanza de Historia y Geografía, con una preocupación por la incorporación de un programa mínimo de Historia de cada país-miembro y discutir acerca de una enseñanza de Historia que es capaz de mostrar enfoques comparativos, que permiten la identificación de los rasgos comunes de identidad y hacer frente a la integración social y el derecho a la diferencia.

Palabras clave: Enseñanza de historia. Grupo de trabajo. Sector Educativo del Mercosur.

\section{Introdução}

O Mercado Comum do Sul (Mercosul), estabelecido por meio do Tratado de Assunção, em 1991 (BRASIL, 1991a), período em que as relações entre Brasil e Argentina começaram a se estreitar, surgiu com o propósito de realizar a integração acelerada das economias nacionais da região da Argentina, do Brasil, do Paraguai e do Uruguai.

A formação do Mercosul está inserida num quadro delineado pelo crescente avanço na área científico-tecnológica, como também pelo processo de globalização ${ }^{1}$ e pela configuração de blocos econômicos, políticos e culturalmente regionais.

O avanço do processo de globalização fez emergir novas formas de relações, que passaram a ser tecidas e negociadas multilateralmente. Evidenciam-se nessas relações a competição entre as regiões e a formação de blocos regionais resultantes da necessidade de integração econômica, política, social e cultural entre os países frente ao cenário internacional que se delineia.

\footnotetext{
${ }^{1}$ O processo de globalização caracteriza-se pela formação de um mercado unificado - onde tudo pode ser comprado, produzido e vendido em qualquer parte do mundo. Ele possibilita a implantação de mercados sem pátria e a integração de mercados regionais que desconhecem fronteiras geográficas (MENDONÇA, 2000). O local e o global se entrelaçam no processo de globalização, formando uma rede em que os dois elementos são transformados, como resultados de suas interconexões (GUIBERNAU, 1997).
} 
O final da década de 1980 assistiu ao colapso do campo soviético, ao fim da Guerra Fria, à aceleração do processo de globalização da economia, à competição entre os países desenvolvidos, à revolução científica e tecnológica e à formação de blocos econômicos como a União Europeia (UE), o Tratado Norte-Americano de Livre Comércio (NAFTA) e a Cooperação Econômica da Ásia e do Pacífico (APEC).

A nova agenda internacional ressaltava a abertura dos mercados internos dos países periféricos e a redemocratização de seus governos (MARTINS, 2007). Nessa perspectiva, os países latino-americanos tornar-se-iam vulneráveis se continuassem isolados. A conscientização por parte dos Estados sul-americanos de que somente por um processo de integração seria possível enfrentar uma série de questões internas e externas de caráter econômico e social fez que essa integração se tornasse realidade (SIMÕES, 2007).

Assim, com o fim dos governos autoritários no Brasil e na Argentina, os limites de ordem imaginária e política foram sendo lentamente derrotados. As controvérsias sobre o aproveitamento de rios e energia entre o Brasil e a região platina e o apoio brasileiro na questão das Malvinas, em 1982, também foram passos fundamentais no desarmamento dos espíritos e na aproximação entre os dois países da América do Sul.

Outro fator que possibilitou a abertura para a retomada do projeto de integração regional foi a diminuição da intensidade de atuação dos Estados Unidos sobre a região sul-americana. Assim, as tentativas de integração, que até então haviam sido dirigidas por protocolos setoriais, assumem "um caráter comercialista, de câmbio livre, de abertura geral e sem proteção setorial” (MARTINS, 2007 , p. 3).

Em 1985, após um longo período de desconfianças e manifestações de rivalidades entre esses dois países, por iniciativa da Argentina, e seu presidente Raúl Alfonsín, e do Brasil, já com o governo civil de José Sarney, foi tomada a decisão política de dar início a um processo de integração econômica, fruto do próprio desejo dos dois países de avançar na complementaridade entre as duas economias.

As negociações com vistas à cooperação e à integração entre os dois países, fruto da superação de décadas de dificuldades de comunicação e desconfianças mútuas, tinham como elemento fundamental a convicção de ambas as partes de que atuando de forma cooperativa seus ganhos seriam consideravelmente superiores aos obtidos em ações de natureza unilateral (LEME, 2006, p. 86).

Em 30 de novembro de 1985, em Foz do Iguaçu, foi assinada a Declaração de Iguaçu, pelos presidentes do Brasil e da Argentina. Alfosín e Sarney, 
influenciados pela concepção europeia de integração regional, vislumbraram a conformação de um mercado comum no Cone Sul. Devido a isso, ambos declararam que a união entre os dois países não deveria ser vista, pelos outros países da região, como uma soma de forças para dominar os demais.

No encontro em Foz do Iguaçu, o presidente Sarney afirmou a seu colega argentino a firme vontade de alterar o curso da história das relações entre os dois países, e defendeu a eliminação de qualquer restrição que pudesse impedir o avanço das negociações rumo à conformação de um mercado comum no Cone Sul (LEME, 2006, p. 155).

Em 1988, Brasil e Argentina estabeleceram o Tratado de Integração, Cooperação e Desenvolvimento, cujo objetivo central era a consolidação do processo de integração bilateral, com o foco de instituir um espaço econômico comum em um prazo de dez anos, a harmonização das políticas aduaneiras, comerciais, industriais, agrícolas, de transporte e comunicação e a organização de políticas monetária, cambial e fiscal (MOMMA, 2001).

Este tratado antecipou alguns dos importantes temas que foram integrados ao Mercosul, em 1991, ao buscar instituir três instrumentos de integração: os objetivos econômicos internos, os objetivos econômicos externos e os objetivos políticos e estratégicos. O primeiro objetivo seria promover o crescimento produtivo dos países com a estabilidade de intercâmbio com os outros parceiros; o segundo objetivo consideraria a criação de um órgão multilateral sul-americano para promover a harmonia de projetos frente a grupos ou Estados mais poderosos, no que refere a economia; e o terceiro objetivo era reconhecer o papel estratégico de embates de natureza política (HAGE, 2001).

A Declaração do Iguaçu e o Tratado de Integração, Cooperação e Desenvolvimento são considerados os dois atos que legitimam a criação do Mercosul. A estratégia de aproximação entre Brasil e Argentina estimulou a construção de uma zona de livre comércio sul-americana, a partir da inserção de quatro países localizados na porção austral da América. Essa cooperação regional foi facilitada pela convergência de interesses entre as partes que possuíam "peso relativo" no contexto global e viam na cooperação um modo de se proteger dos efeitos da globalização (MARTINS, 2007). Nascia, assim, o Mercado Comum do Sul (Mercosul), com a participação do Brasil, da Argentina, do Paraguai e do Uruguai.

A assinatura do Tratado de Assunçãó2, em março de 1991, marca o nascimento formal do Mercosul. Neste documento, foram fixados os prazos, as metas e os instrumentos para a construção de um mercado comum.

\footnotetext{
${ }^{2}$ O Tratado de Assunção foi firmado pelos presidentes: Carlos Saúl Menem, da Argentina, Fernando Collor de Mello, do Brasil, Luis Alberto Lacalle Herrera, do Uruguai, Andrés Rodriguez, do Paraguai; e pelos Ministros das Relações Exteriores: Guido Di Tella, da Argentina, Francisco Rezek, do Brasil, Hector Gros Espiell, do Uruguai, Alexis Frutos Vaesken, do Paraguai (MOMMA, 2001).
} 
Saraiva (1995) observa que a formação do Mercosul foi resultado da vontade política dos governantes dos países contratantes de implementar decisões para o processo de integração. Segundo ele, o Mercosul está sustentado em uma visão restritiva dos parceiros, e é quase um imperativo de sobrevivência diante das dificuldades de construção de regras estáveis no sistema internacional. Não é somente um mercado, pois as dimensões sociais - nas quais se insere a educação - começaram a tomar relevo a partir desse processo de integração.

\section{O Setor Educacional do Mercosul e as ações, reflexões e perspectivas do Grupo de Trabalho no Ensino de História}

O Tratado de Assunção (BRASIL, 1991a) apontou a questão econômica como um dos principais motivos para a criação do Mercosul. Declara, na introdução, que a ampliação das atuais dimensões de seus mercados nacionais constitui condição fundamental para acelerar os processos de desenvolvimento econômico com justiça social.

Entretanto, a necessidade de integração não somente econômica, mas também política, social e cultural entre os países que compõem um bloco regional, é cada vez maior. Essas políticas de integração, em outros âmbitos, são justificadas pela necessidade de investimento estratégico na formação de recursos humanos e pela integração cultural e científica por meio do intercâmbio entre distintos países (RAIZER; FACHINETO; NEVES, 2006).

No caso do Mercosul, a educação entrou na pauta da discussão desde o início. Assim, a necessidade de uma integração educacional foi colocada em pauta ainda no ano de 1991, na reunião ocorrida em 13 de dezembro, com os Ministros ${ }^{3}$ da Educação da Argentina, do Brasil, do Paraguai e do Uruguai, na cidade de Brasília. Nesta reunião, foi assinado o Protocolo de Intenções, o qual considerava

- Que a Educação tem um papel fundamental para que esta integração se consolide e se desenvolva;

- Que a herança cultural dos povos latino-americanos e, particularmente, dos Estados-Membros do MERCOSUL, é comum;

- Que estes povos comprometeram-se ante a História a empreender esforço conjunto que os conduza à prosperidade, ao progresso e ao bem-estar, com justiça social;

- Que o fator humano e a qualidade dos habitantes da região constituirão uma sólida garantia de êxito no processo de integração;

- Que a melhoria dos fatores de produção requer necessariamente a elevação dos níveis de educação e de formação integral das pessoas;

\footnotetext{
${ }^{3}$ Estiveram presentes nesta reunião os ministros Antonio Salonia, da Argentina, Antônio Teixeira de Souza Júnior, do Brasil, Hugo Estigarribia Elizeche, do Paraguai, e Guillermo García Costa, do Uruguai.
} 
- Que para fortalecer a ampliação das atuais dimensões de seus mercados nacionais, a livre circulação de bens, serviços e fatores de produção, é fundamental considerar a Educação como elemento dinamizador que permitirá acelerar os processos de desenvolvimento econômico com justiça social e consolidar o caminho da integração;

- Que a Educação depende, em grande parte, da capacidade dos povos latino-americanos de se reencontrarem nos valores comuns e na afirmação de sua identidade ante os desafios do mundo contemporâneo;

- Que a Educação, como processo gerador e transmissor de valores e conhecimentos científicos e tecnológicos, além de sua finalidade formadora e produtiva, pode constituir-se em meio eficaz de modernização para os Estados-Membros. (BRASIL, 1991b, p. 1).

Gadotti (2007), entretanto, compreende que não é possível ser ingênuo e pensar que a educação pode sozinha resolver o problema da integração, mas ela é um fator importante de formação e consolidação de uma integração, já que esta se realiza a partir do momento em que as partes se reconhecem, mutuamente, como diversas. Neste aspecto, falar de integração é falar de ampliação e interação de laços econômicos, políticos, sociais e culturais, falar das semelhanças e das diferenças existentes e perceber que:

[...] a grande semelhança da América Latina está na sua unidade linguística, espanhol e português, línguas irmãs, mutuamente inteligíveis e base de nossa unidade cultural. As diferenças culturais devem ser defendidas e preservadas. Integrar não é dissolver ou justapor. É colocar em comum (GADOTTI, 2004, p. 03).

A tentativa de constituição do Mercosul exigiu a adoção de medidas econômicas, tarifárias, técnicas e sanitárias dos produtos manufaturados por parte dos países-membros. Tornaram-se necessários a elaboração de programas de formação de recursos humanos, a obtenção de padrões educacionais mínimos na região, o estabelecimento de critérios de equivalência de diplomas de nível superior, técnico e médio e conhecimento mútuo entre os países do bloco (WASSERMAN, 1999).

Assim, na reunião entre os Ministros da Educação ocorrida em 13 de dezembro de 1991, decidiu-se criar a Comissão dos Ministros da Educação, propondo ao Conselho do Mercado Comum (CMC) a organização de um subgrupo de trabalho no campo educacional.

Em 17 de dezembro de 1991, o CMC, reunido em Brasília, decidiu, por meio da Resolução 07/91, criar a Reunião de Ministros de Educação (RME), cuja função era propor, por intermédio do Grupo Mercado Comum, medidas visando à coordenação das políticas educacionais nos Estados-Partes. Com a 
entrada em vigor da RME, é institucionalizado o Mercosul Educacional, oficialmente chamado de Setor Educacional do Mercosul (SEM).

Para assistir às Reuniões dos Ministros de Educação do Mercosul, foi constituído o Comitê Coordenador Regional (CCR), encarregado de propor políticas e estratégias educacionais para a integração regional e coordenar atividades do setor educacional dos Estados-Partes. O CCR era composto por uma delegação nacional de cada Estado-Parte, presidido por um representante do Ministério da Educação. Ele poderia criar Comissões Técnicas Regionais (CTR) e Grupos de Trabalhos (GT) (MOMMA, 2001). Entre os grupos de trabalhos criados, constituiu-se o GT no ensino de História e Geografia.

Uma das primeiras ações deste GT se deu durante a V Reunião de Ministros da Educação, ocorrida em 21 de dezembro de 1993, em que foi realizado um trabalho preliminar de discussão acerca de conteúdos mínimos de História, assim como dos esquemas conceituais e dos critérios metodológicos que orientariam a inclusão de conteúdos específicos de cada país nas reformas curriculares dos demais países (SARAIVA, 1998).

Em 1994, na primeira reunião de especialistas de história que compunham o GT, ocorrida na cidade de Buenos Aires, foi acordada a produção de módulos de História, que deveriam ser redigidos pela Comissão Técnica Nacional Argentina do Mercosul Educacional, a partir de materiais e recomendações encaminhados pelos outros países. Os resultados desde trabalho foram encaminhados, em forma de "rascunho", pelo Ministério da Educação da Argentina para os demais países.

No mesmo ano, na VII Reunião de Ministros da Educação dos Países do Mercosul, realizada em Ouro Preto, foi registrado o compromisso de concluir o trabalho de redação dos módulos de História no primeiro semestre de 1995. No entanto, a reunião ${ }^{4}$ dos delegados que subsidiavam e preparavam a agenda para a Reunião dos Ministros avaliou os módulos e concluiu que eram inviáveis. Nesse sentido, a posição do Brasil foi fundamental na reunião, ao apresentar o caráter diversificado dos sistemas educacionais de cada país, uma vez que, no caso brasileiro, a descentralização educacional tornaria o módulo de História apenas como uma peça recomendatória.

Além desse aspecto exposto pelo Brasil, o texto dos módulos, preparado pelos especialistas argentinos, apresentou problemas quanto a sua abordagem. Segundo Saraiva (1998), ele não trazia os resultados mais consagrados das pesquisas e era marcado pelo nacionalismo historiográfico de cada país.

Diante desta complexidade para a adoção dos módulos, encaminhou-se uma nova proposta de trabalho para os especialistas de História. Foi proposto

\footnotetext{
${ }^{4}$ Saraiva (1998) descreve que esta foi a XIV Reunião do Comitê Coordenador Regional do SEM.
} 
que - com base nos conteúdos mínimos que haviam sido sugeridos no seminário de especialistas, ocorrido anteriormente em Buenos Aires - os conteúdos fossem encaminhados e servissem como elementos de apoio no processo de discussão dos parâmetros curriculares nacionais, que estavam em andamento em todos os países que integram o Mercosul.

A nova proposta de trabalho, além de possibilitar o avanço metodológico no tema, também permitiu a proposta de um quadro contextualizador para a inserção gradual de conteúdos de História na perspectiva de integração. Dessa forma, em outubro de 1995, em Brasília, na reunião de especialistas em que se discutiu a nova proposta, foi redigido o documento "Para uma História e uma Geografia da Integração Regional”, em relação ao qual Saraiva observa:

A preocupação dos especialistas, em Brasília, era vincular a dimensão da construção de uma consciência social favorável ao processo de integração por meio do estímulo ao debate da história regional do Prata, do envolvimento dos quatro países em uma matriz histórica que tem muito em comum a superação dos nacionalismos históricos. A cautela para não impor conteúdos excessivamente fechados levou a que o documento discutisse a "coexistência dos aspectos compartilhados e dos que conferem características e dinâmicas particulares a cada uma dessas sociedades" (SARAIVA, 1998, p. 19).

Como princípios e atitudes sugeridos na discussão dos conteúdos mínimos de História em cada um dos países do Mercosul, Saraiva (1998) destaca a ampliação das visões restritivas do ângulo nacional a partir do enfoque regional, sustentado na solidariedade, na integração e na globalização, e a vinculação dos processos nacionais e regionais em suas dimensões sócio-histórica e socioespacial diante do contexto internacional.

Entre os eixos comuns para o desenvolvimento dos conteúdos específicos correspondentes em cada país, o documento trouxe a inclusão da história das sociedades e das culturas indígenas americanas, a diversidade cultural e os aspectos comuns, a construção da democracia e o processo de integração na região.

Além dessas ações, foram realizados pelo GT quatro seminários de especialistas dessas áreas. Em 1997, ocorreu o primeiro, e o último foi realizado em 2004, em Valparaíso, Chile. No entanto, de acordo com a ata $n^{\circ} 2 / 07$ da LXI Reunión del Comité Coordinador Regional del Sector Educativo del Mercosur, estava previsto para outubro de 2007 o V Seminário de História e Geografia, em Florianópolis, Brasil. ${ }^{5}$

\footnotetext{
${ }^{5}$ Diante do relato desta ata, fiz contato com a Assessoria Internacional, em Brasília, que me enviou uma mensagem eletrônica, em 23 de julho 2009, informando que o V seminário foi cancelado da data prevista e adiado em duas ocasiões, no primeiro e no segundo semestre de 2008, em razão de sua desaprovação pelo CCR. Segundo a assessoria, o seminário em questão não consta mais no cronograma do Setor Educacional do Mercosul.
} 
O primeiro seminário ${ }^{6}$, ocorrido em 1997, apresentou discussões em duas mesas-redondas e sistematizou recomendações sobre o enfoque regional nas atuais propostas curriculares dos países do Mercosul, sobre os temas comuns aos países-membros no ensino de História e sobre os livros didáticos e as novas tecnologias no ensino de História em uma perspectiva regional.

No que se refere à primeira mesa-redonda, o tema proposto foi a trajetória e as perspectivas da história no Mercosul. A especialista argentina Silvia Finocchio destacou que, no contexto das atuais transformações culturais, o que tem chamado atenção no processo de globalização é a aceleração dos fluxos culturais, gerando mudanças de percepção das categorias de tempo e de espaço.

Diante dessa dinâmica cultural e das mudanças na percepção de tempo e espaço, Finocchio questionou de que maneira o ensino de História poderia contribuir para a democratização da integração em termos culturais. Como resposta a essa pergunta, a autora considera importante refletir a respeito da função da História no contexto do Mercosul; divulgar o que foi produzido em termos de conhecimentos históricos sob uma perspectiva regional; definir conteúdos escolares que sejam legitimados por essa produção; advertir sobre os problemas da circulação de livros e do estado de pobreza das bibliotecas em relação a esta temática; e, por último, formar redes de profissionais de diversos tipos.

O representante brasileiro José Flavio Sombra Saraiva, ao analisar a trajetória do campo da História no Mercosul até a realização do primeiro seminário regional, sinalizou a existência de alguns problemas que precisam ser tratados, a fim de que as discussões pudessem ser desenvolvidas no decorrer dos anos consecutivos.

Saraiva, em primeiro lugar, indica como problema a falta de uma estratégia comum aos quatro países quanto ao papel da educação em História no processo de formação de uma consciência histórica comum. Para o autor, a dimensão utilitária que se tentou dar aos módulos indica que a visão meramente funcional tentou impor-se à tarefa de ampliação do horizonte da discussão sobre o tema.

Tomando o significado dado por Rüsen (2001, p. 59) para consciência histórica - quando a descreve como o local em que o passado é levado a falar; e ele fala por causa da carência de orientação da vida prática atual diante de suas intensas experiências no tempo, e que o homem só pode viver no mundo, só consegue relacionar-se com a natureza, "com os demais homens e consigo mesmo se não tomar o mundo e a si mesmo como dados puros, mas, sim, interpretá-los em função das intenções de sua ação e paixão" -, pode-se pensar que a formação da consciência histórica comum, indicada por Saraiva, tem a pretensão de que o

\footnotetext{
${ }^{6}$ As exposições trazidas pelos especialistas no primeiro seminário estão descritas no livro $O$ ensino de História e Geografia no contexto do MERCOSUL, organizado por Marilda Almeida Marfan.
} 
papel da educação em História seja dar identidade aos sujeitos latino-americanos, fornecendo-lhes uma dimensão temporal e uma orientação para guiar suas ações.

Quanto aos demais problemas sinalizados por Saraiva, este indica, em segundo lugar, a ausência de uma resposta satisfatória para a pergunta acerca das razões que alimentam a revisão da história dos países envolvidos no movimento de integração regional no Mercosul. Segundo o autor, apesar das fortes doses nacionalistas ainda presentes e do desconhecimento que os países têm acerca dos textos disponíveis, dos livros didáticos e dos resultados de pesquisas acadêmicas no campo histórico, existem tradições historiográficas nos quatro países que, embora ainda isoladas, poderiam ser aproximadas pela via do intercâmbio de professores e de especialistas.

Em terceiro lugar, Saraiva expõe como um problema a exagerada tendência, nos enfoques integracionistas, para a acomodação e o silêncio dos conflitos históricos em favor da construção de uma imagem romântica e necessária para a integração. Segundo o autor, é necessário tanto perceber que não existe uma história neutra como também não cair na infeliz ideia de dividir a história dos povos dos quatro países signatários em antes e depois do Mercosul.

Para este especialista, pode ser interessante observar as novas experiências de discussão dos currículos que estavam sendo realizadas nos países. Afinal,

[...] o Mercosul e a própria América Latina são somente capítulos em uma multiplicidade de processos históricos regionais, locais e internacionais que não podem ser desvinculados uns dos outros sob o risco de estarmos produzindo, para os nossos alunos, uma história excessivamente paroquial (SARAIVA, 1998, p. 21).

Em quarto e último lugar, ele não indica necessariamente um problema, mas pensa que há duas maneiras de se tratar a História no processo negociador da educação do Mercosul:

Na primeira, a educação é o centro civilizador e empreendedor de uma utopia viável que vê na inclusão de uma nova História e de uma nova Geografia nas salas de aula e nos livros didáticos uma oportunidade original de desenvolver social e culturalmente os povos da região e de estimular, em nossos alunos, a adoção de atitudes críticas diante das modernizações conservadoras e da desidentificação das nações e dos valores da solidariedade. Na segunda, a História e a Geografia servirão apenas para conservar a dominação, para descaracterizar as nações e um mero instrumento de divulgação de oportunidades de mercado, do fetiche da globalização desinteressada pela formação ética e humana dos nossos filhos (SARAIVA, 1998, p. 22).

O último texto referente a esta primeira mesa-redonda foi da uruguaia Adela Pereyra. Ela delineia que os educadores, mestres e professores dos países 
envolvidos no Mercosul têm o desafio de procurar enfoques, estratégias e ações que fomentem e possibilitem a integração que esses quatro povos têm decidido realizar. Não se trata mais de formar os cidadãos nacionais de cada Estado, mas de formar um cidadão inserido no processo de globalização, capaz de manusear e integrar simultaneamente diversas dimensões espaciais e temporais.

A segunda mesa-redonda procurou levantar, apresentar e discutir as tendências da produção historiográfica observada nos países do Mercosul, em busca de novas possibilidades e estratégias de abordagem regional, tanto no campo da pesquisa como no do ensino, em curto, médio ou longo prazo.

Com essa pequena introdução a respeito do que seria discutido na mesa-redonda, ficam evidentes as diferenças entre as duas mesas-redondas. Enquanto na primeira foi possível ver que as questões apareciam como desafios, na segunda as questões, que serão expostas a seguir, desenvolveram-se em torno das ações que poderiam ser viabilizadas.

Nesta mesa-redonda, o argentino Alejandro Eujanian sinalizou que o que tem caracterizado as tradições historiográficas na América do Sul é o escasso diálogo entre as mesmas. Ele destacou como problema mais grave da ausência de diálogo a pobreza na circulação das produções realizadas por cada país, especialmente a brasileira, pois são muito poucos os livros de historiografia brasileiros traduzidos para o castelhano.

Para Eujanian, os motivos prováveis para a abertura dessa brecha na trajetória dos países latino-americanas são, em primeiro lugar, a juventude de alguns Estados nacionais, que fundaram sua legitimidade, sua soberania e sua ideia de cidadania baseados na ênfase às diferenças culturais, políticas, sociais e étnicas, especialmente entre os países limítrofes, que apresentam um passado próximo de confrontos e vivenciam uma série de problemas fronteiriços na atualidade. Em segundo lugar, a própria historiografia privilegiou, a partir da segunda metade do século XIX, a função central de outorgar a esses Estados um passado cujas raízes estariam na colônia. Por último, surge a necessidade de atender às diferenças entre os diversos países com respeito a suas respectivas bases institucionais e práticas profissionais. O autor cita como exemplo a escassa autonomia de algumas instituições acadêmicas em relação ao Estado, como no caso da Argentina e do Brasil, o que provocou efeitos desastrosos para a continuidade das pesquisas, bem como para a formação de recursos humanos. Frente a esses motivos, Eujanian entende que o desafio é refletir sobre o modo como circula nosso saber e sobre a função social do conhecimento.

A especialista brasileira Heloisa Reichel, numa tentativa de avaliar as abordagens presentes na produção historiográfica do Mercosul, enfatizou a presença de um forte viés nacionalista, a separação entre as histórias das áreas 
de colonização portuguesa das de colonização hispânica e o predomínio de uma história política que privilegia - no que se refere às relações internacionais - os conflitos e as disputas que existiram entre os países do bloco regional. Para ela,

[...] é necessário estimular as abordagens comparativas e as temáticas que possibilitem a identificação de traços de identidade comuns ou de aproximação entre os países, em vez de narrar uma história delimitada pelos limites geopolíticos do Estado-nação e pelos antagonismos e diferenças que marcaram as relações entre os mesmos (REICHEL, 1998, p. 55).

Para o uruguaio Alberto Ferré, o horizonte a partir do qual se poderia fazer a história inclusiva dos quatro países do Mercosul seria o contexto da América Latina como um todo, dentro da perspectiva de sua atualidade dinâmica e de suas raízes.

Diante dessas questões, levantadas nas mesas-redondas do I Seminário, localizou-se, nas últimas páginas do texto organizado por Marfan, a descrição de outra proposta de temas comuns para o ensino de História dos países que integram o Mercosul, selecionados pelo grupo de trabalho:

1. Estudo histórico das diversas etnias.

2. Fronteiras com espaço de intercâmbio e isolamento.

3. Passado colonial na perspectiva de estudos comparados.

4. Estudo dos conflitos entre Estados nacionais numa perspectiva regional.

5. As ditaduras militares recentes na América Latina e os circuitos do exílio.

6. A produção cultural numa perspectiva histórica (MARFAN, 1998, p. 11-12).

O questionamento, que nos perpassa frente aos temas indicados acima, é que eles foram discutidos e descritos em 1997, quando a proposta curricular da Argentina já havia sido publicada e a do Brasil estava sendo definido. Seria possível pensar que esses temas chegaram ou chegam às escolas por meio dos livros didáticos, ou da formação inicial ou continuada que os professores têm transmitido em sala de aula aos alunos?

O II Seminário Bienal sobre o Ensino de História e Geografia ocorreu em Montevidéu, nos dias 30 de novembro e 1 e 2 de dezembro de 1999. Os trabalhos apresentados sobre o ensino de História foram divididos em três grupos de trabalho: "História e Memória", "Investigações sobre a Didática da História" e "Propostas sobre Experiência de Aula no Ensino de História". Do grupo de trabalho "História e Memória", a pesquisadora argentina Liliana Cattáneo sinaliza que não há desconhecimento no fato de que, na América Latina, os Estados nacionais embarcaram em um duplo processo de invenção e celebração de seus próprios passados, desdenhando tanto a dimensão de uma identidade regional como as identidades locais anteriormente construídas. 
A autora entende que é preciso evitar cair na falácia de considerar que, uma vez levantado o véu dessas histórias nacionais artificiais, apareceriam as autênticas histórias das sociedades latino-americanas. Para ela, levar em consideração essa circunstância possibilita a decisão política de consolidar os intercâmbios necessários de investigadores e docentes nos países da região, de forma a promover um ensino de História menos prejudicial ao outro e insistir na elaboração de materiais didáticos que abandonem a celebração das supostas glórias do passado da nação e se inscrevam num horizonte mais aberto.

Tratando do Brasil, a especialista brasileira Kátia Baggio descreve que a necessidade de construir e fortalecer uma identidade nacional levou muitos historiadores, cientistas sociais e ensaístas a reforçar as diferenças do Brasil em relação aos demais países americanos. Esse distanciamento, de certa maneira, foi incorporado pela sociedade brasileira, e, por isso, a identificação dos brasileiros como latino-americanos é fluida, variável, mais ou menos presente, dependendo das circunstâncias e do momento histórico. Para Baggio, não há dúvida de que as diferenças são, em geral, mais destacadas do que as similitudes. "A América hispânica - vista a partir de olhares brasileiros - é uma 'outra' América, ainda que façamos parte deste todo complexo e contraditório denominado América Latina” (II SEMINÁRIO BIENAL, 1999, p. 18). No entanto, a autora observa que, a despeito da construção de uma memória - que insistiu no distanciamento entre o Brasil e os países hispano-americanos e caribenhos -, ocorre um avanço significativo no que diz respeito às pesquisas na área de história latino-americana no Brasil, que se deve tanto pela criação, em 1993, da Associação Nacional de Pesquisadores de História Latino-Americana e Caribenha (ANPHLAC) - cujos objetivos são o estímulo e a divulgação dos trabalhos historiográficos produzidos no Brasil acerca da história da região - como pelos programas de pós-graduação, que têm sido de fundamental importância para o desenvolvimento da pesquisa historiográfica no Brasil nas últimas décadas.

Ainda do grupo de trabalho "História e Memória", os especialistas uruguaios Alberto Ferré, Pedro Gatti e Barbara Díaz observam que, hoje, o Cone Sul americano encontra-se na encruzilhada da integração, pois existe um acordo quanto à importância dessa integração, porém surgem problemas para instrumentá-la e definir que tipo de integração se quer construir. Para esses especialistas, a História tem uma resposta a essa questão, que está no fato de que a integração é, na realidade, uma reintegração, um retorno à antiga unidade americana. Estudar essa antiga unidade leva a rastrear as origens, a conhecer adequadamente a unidade de herança multicultural, para que assim se possa começar a forjar um projeto de inclusão daquilo que é comum.

Ferré et al. (1999) concluem o texto observando, primeiramente, que conhecer e valorizar aquilo que é próprio de cada comunidade é uma premissa 
indispensável para o mútuo conhecimento e, em segundo lugar, que, para o enriquecimento comum, um projeto de ensino de História, formulado por meio dessas premissas, redundará no resgate revitalizante e coerente do nosso ser americano.

Já dentro do grupo de trabalho "Investigação da Didática de História", a historiadora brasileira Circe Bittencourt fez um levantamento das pesquisas realizadas no Brasil - na área de ensino de História, na última década do século $\mathrm{XX}$ - e sinalizou a existência de poucas pesquisas a respeito do ensino de História da América Latina e do Mercosul. Para ela, a pequena produção poderia ter suas raízes em épocas anteriores, quando as necessidades mais urgentes levaram alguns historiadores a se dedicar à discussão sobre a identidade nacional.

Ainda neste grupo de trabalho, a pesquisadora Adela Pereyra destacou, em pesquisa realizada com os professores da rede pública de ensino básico no Uruguai, que, entre eles, há um desconhecimento a respeito do ensino de História dos demais países que compõem o Mercosul e não existe uma percepção a respeito do Mercosul como uma etapa para chegar a uma integração latino-americana. Nesse sentido, Pereyra enfatiza que a abordagem do tema da integração parece ser uma transversalidade que deve romper as fronteiras das disciplinas, necessitando estar sempre presente nas futuras programações do grupo de trabalho.

No que se refere ao grupo de trabalho "Propostas sobre Experiência de Aula no Ensino de História", as especialistas brasileiras Maria de Fátima Sabino Dias e Maria José Reis expuseram o Acordo de Cooperação entre o Colégio de Aplicação da Universidade Federal de Santa Catarina/Brasil e a Escola Superior de Comércio Manuel Belgrano, da Universidade Nacional de Córdoba/ Argentina, iniciado em novembro de 1992. Segundo as autoras, o acordo, conhecido no Colégio de Aplicação como "Projeto Córdoba", promove o intercâmbio cultural de alunos e professores de ambas as instituições de ensino. Assim, "ver o outro", conhecê-lo, valorizá-lo em sua realidade e refletir sobre o diálogo entre as culturas tem se apresentado como mais um desafio para o cotidiano das escolas, em função dos inúmeros desdobramentos que se colocam na prática e na consecução dos objetivos específicos do intercâmbio.

Para além do intercâmbio, o Projeto Córdoba realizou encontros com os professores e um minicurso com o objetivo de trazer discussões teórico-metodológicas com professores da área de Geografia ou disciplinas afins. Quanto ao campo da pesquisa, Dias e Reis descrevem que o Projeto Córdoba está elaborando um diagnóstico de como ocorreu o ensino de História da América, em ambos os países, no período de 1985 a 1995. Com isso, pretende-se rever a interpretação que fazemos sobre nós mesmos e sobre os "outros" latino-americanos e contribuir para eliminar as distorções, frequentemente existentes nas histórias 
nacionais, que geram preconceitos e hábitos discriminatórios, bem como para formar uma consciência cidadã, que transcenda a nação e estimule a integração cultural entre Brasil e Argentina.

Os pesquisadores uruguaios Hilda Malán, Schubert Barragán e Silvana Casero expõem a Educação Patrimonial, tomando o conceito de que não diz respeito somente ao patrimônio material, mas se trata também de um patrimônio ético que estabelece valores, como os princípios universais de solidariedade, democracia, justiça social, paz, tolerância, etc. Nesse sentido, os autores compreendem a importância de incluir a Educação Patrimonial como um conteúdo curricular transversal, nos diferentes níveis da Educação Básica, porque permite o desenvolvimento e a discussão de valores que promovem a formação de uma consciência "mercosuliana", que é uma responsabilidade de todo o corpo docente e dos educandos dos países associados.

Assim, no II Seminário Bienal, os especialistas da área de História levantaram algumas conclusões:

- É necessário impulsionar investigações históricas compartilhadas, sobre os temas comuns acordados no primeiro seminário;

- É preciso realizar estágios de docentes e estudantes procedentes de diferentes países que integram o Mercosul;

- Deve-se implementar um banco de dados sobre produções historiográficas, centros de investigação, investigadores, linhas de investigação, referentes à história da América Latina;

- É importante promover intercâmbios anuais de experiências dos docentes com os temas comuns, como migração, fronteiras vivas e móveis, as ditaduras militares e a passagem pela via democrática republicana e as questões étnicas indígenas;

- O Mercosul Educacional deve difundir seus avanços por distintos meios, para estabelecer questões relativas à educação para a inclusão na agenda dos grupos de professores.

Com esses dados, percebe-se que, tanto no primeiro seminário quanto no segundo, persistem os temas da formação de redes de profissionais e do fortalecimento de intercâmbios de investigadores e docentes. Gadotti (2007, p. 7) observa que, "tradicionalmente", a cooperação e a integração entre os países em relação a educação, ciência, tecnologia e cultura têm sido predominantes no Ensino Superior, sendo as universidades as maiores beneficiadas na convivência entre os países da América Latina. Mas o autor descreve que, mesmo havendo essa integração acadêmica, vários pontos precisam ser aprofundados, e, entre eles, está “a produção de material didático imbuído do espírito de integração que, por exemplo, aprofunde o conhecimento de nossas culturas e nossa história comum". 
Nesse sentido, tais percepções a respeito dos limites dos intercâmbios de investigadores e docentes e da necessidade de aprofundar-se a integração acadêmica - que onde se dá a formação inicial e continuada dos professores da Educação Básica - levam-nos a pensar, num primeiro momento, que o que se veicula sobre a América, no ensino de História das últimas séries da Educação Básica, é fruto muito mais das permanências do que das mudanças inseridas na cultura escolar.

Entre 22 e 24 de agosto de 2002 ocorreu o III Seminário Bienal de História e Geografia, na cidade de Buenos Aires. Tratando do que foi exposto neste seminário, a pesquisadora uruguaia Bárbara Díaz relatou que o papel da História na formação de cidadãos para a integração necessita de um enfoque que colabore notavelmente com essa formação:

[...] por un lado, realizando una labor positiva de estudio de proyectos integradores, de sus raices, sus dificultades, sus logros; por otro, baciendo un estudio critico del proceso de formación del Estado-nación para valorar en qué medida ello ba constituido y constituye aún boy una rémora a la integración (ARGENTINA, 2002, p. 05).

Díaz sinaliza que, para que isso ocorra, é necessário considerar esse processo em sua dimensão ética, pois uma integração supõe mudança no comportamento das pessoas e exige dos cidadãos o desenvolvimento de novas atitudes, novos hábitos e valores que fomentem a amplitude de horizontes e a abertura para a diversidade.

Ariel Denkberg, da Universidad de Buenos Aires, analisa a questão do ensino de História e Geografia na formação de uma cidadania crítica, que respeite a diversidade nos processos de integração regional. Segundo ele, o conceito de cidadania, que deve orientar o ensino de História, precisa contemplar, ao mesmo tempo, a integração social e o direito à diferença, a conformação de práticas políticas compartilhadas e a valorização de múltiplas iniciativas de participação e organização política, uma cidadania ativa e uma sociedade pluralista que não afirme sua própria identidade, negando o valor das outras.

A pesquisadora María Elena Caillet Bois, da Universidad Nacional de Córdoba, na Argentina, pontua que uma das formas utilizadas para colonizar a história tem sido a apresentação de periodizações que, de alguma maneira, evitariam o olhar sobre a América Latina e priorizariam o olhar sobre uma periodização europeizante ${ }^{7}$. Bois entende que o modo de contribuir para

\footnotetext{
${ }^{7}$ Citron (1990) expõe essa mesma preocupação ao tratar do ensino de História na França e questiona se a História continuará a existir na sua forma eurocêntrica e institucional, seguindo as normas de um positivismo que confunde um enunciado particular com uma verdade que se coloca como absoluta. Para a autora, a manutenção da ordenação ocidental do passado nas escolas não leva em conta nem a pluralidade dos sujeitos nem a dos espaços-tempo. Ela garante os genocídios culturais e as destruições realizadas pelo Ocidente, como as cruzadas, os massacres aos índios e o tráfico dos negros, em nome de sua superioridade religiosa e intelectual.
} 
a descolonização da história deveria ser por intermédio de periodizações personalizadas que permitissem o enfoque centrado na América Latina. Essas periodizações poderiam mostrar os problemas compartilhados pelas nações, insistindo nas singularidades, sem se esquecer de inseri-las no contexto mais amplo, de modo que "cuestiones como el imperialismo, o las consecuencias de la segunda revolución industrial, las guerras mundiales etc, puedan verse, no como un problema especifico de cada país, sino como un problema común" (ARGENTINA, 2002, p. 06).

De acordo com Bois, isso exigiria um novo olhar, a partir da educação, que deveria estar centrado em três eixos:

Necesidad de descolonizar la historia.

Desmitificar el antropocentrismo reinante.

Educar para la comprensión. (ARGENTINA, 2002, p. 02)

Bois propõe, então, apresentar uma periodização diferente, que permita trabalhar a descolonização e recuperar o corpo disciplinar válido que a sociedade reconhece no presente. Para isso, ela considera que uma periodização deva basear-se nas trocas estruturais ou nas trocas de paradigmas que têm se sucedido ao longo do tempo.

A pesquisadora divide a história latino-americana em quatro paradigmas: primeiros povoadores, imposição de novas pautas culturais, da independência política a novas independências e globalização. No estudo dos primeiros povoadores, parte-se da aparição do homem americano até a conquista no século XV. O paradigma "imposição de novas pautas culturais" trata da destruição das formas de vida dos indígenas e o aparecimento de novos conceitos, como conquista, cristianismo e aculturação. No estudo da independência política a novas independências, Bois considera importante a influência das novas ideias advindas da Revolução Francesa e da Revolução Industrial inglesa; a entrada dos países latino-americanos no mercado mundial, como provedores de matéria-prima - Argentina com a carne, Brasil com o café, Chile com o cobre; as guerras mundiais dando espaço para a industrialização - consequentemente surgindo a burguesia industrial e a classe operária; o populismo, com o peronismo na Argentina e o varguismo no Brasil; a abertura para o capital estrangeiro e a dívida externa; algumas tendências democráticas; os golpes militares no Brasil, na Argentina e no Chile; e a recuperação democrática. O último paradigma pontuado por Bois é a globalização, que deve ser caracterizado por uma economia mundializada e o retorno à democracia.

Bois assinala que esses paradigmas não são os únicos que podem ser apresentados, sendo possíveis outras projeções. Entretanto, a pesquisadora observa que essa forma de ensinar, "sin dudas, permitirá a nuestros alumnos reconocerse como parte de la historia, y si bien no podrán hacerse cargo de la historia pasada, 
si podrán responsabilizarse de la historia por venir. Que no es poco para el mundo actual' (ARGENTINA, 2002, p. 9).

Sobre o IV Seminário, não temos referências de textos, autores e especialistas que estiveram presentes. Entretanto, lendo as atas contidas no sítio oficial do Mercosul, encontramos uma referência sobre o IV Seminário na ata $n^{\circ}$ 04/04, da LI Reunião do Comitê Coordenador Regional do Setor Educacional do Mercosul. $\mathrm{Na}$ ata, entre os informes sobre as atividades da Comissão Regional Coordenadora da Educação Básica (CRC-EB), há uma citação que se refere ao IV Seminário:

IV Seminário de História e Geografia

Considerando a declaração feita pelos participantes do IV Seminário, o CCR decidiu promover outras atividades e aprofundar as ações de integração relacionadas ao tema de História e Geografia. Acolheram as sugestões de ações tais como: um programa de escolas sem fronteira; a formação e capacitação docente; a elaboração de materiais; a construção de banco de dados; e a criação de equipes de pesquisa. O CCR acordou instruir a CRC-EB e CRC-ES ${ }^{8}$ a fomentar iniciativas que tratem desta temática (BRASIL, 2004, s/p).

\section{Considerações finais}

No desenvolvimento deste artigo, expusemos o processo de consolidação do Mercosul e fizemos uma incursão nas atividades do Grupo de Trabalho no Ensino de História e Geografia (GT), do Setor Educacional do Mercosul, apresentando suas ações, reflexões e perspectivas.

Ao tratarmos da formação do Mercosul, vimos que a questão econômica foi um dos principais motivos para sua criação, porém o Mercosul, desde sua constituição, preocupou-se com a educação, embora essa preocupação não possa ser considerada um fator isolado dos demais processos de integração que vinham ocorrendo simultaneamente em outros continentes. A educação passou a ser um dos eixos importantes da transformação das economias e do perfil produtivo das integrações regionais.

Assim, percebemos que o Setor Educacional do Mercosul reconhece a importância da educação como estratégia para o desenvolvimento da integração regional, propondo políticas e estratégias que viabilizem esse processo. Nesse sentido, essas políticas e estratégias favoreceram a formação do grupo de trabalho.

O GT tem colocado em sua pauta projetos e atividades sobre o ensino de História que viabilizem uma integração regional. Os seminários realizados pelo GT fizeram parte desses projetos de planos de ação.

\footnotetext{
${ }^{8}$ Comissão Regional Coordenadora de Educação Superior.
} 
Das discussões trazidas pelos especialistas nos seminários, percebemos que houve a preocupação do GT em incorporar conteúdos curriculares mínimos de História de cada um dos países do Mercosul. Isso gerou a tentativa de produzir módulos de História comuns aos quatro países, a assinatura de um documento que previsse a incorporação gradativa dos conteúdos curriculares mínimos de História de cada país e, por fim, a redação, em 1995, de um documento que definia os eixos comuns para o desenvolvimento dos conteúdos específicos de cada nação - incluindo a história das sociedades e das culturas indígenas americanas, a diversidade cultural e os aspectos comuns, a construção da democracia e o processo de integração na região.

Isso, porém, não sinaliza um consenso no parecer dos especialistas de cada país, algo que pode ser visto pela posição contrária do Brasil quanto à utilização de módulos de História, uma vez que o país entende que cada Estado-Parte possui um caráter diversificado no sistema educacional.

Nesse sentido, as diferenças também são sinalizadas nas discussões realizadas nos seminários, uma vez que o tema referente aos conteúdos curriculares permaneceu ao longo dos encontros. No III Seminário, Bois traz a proposta de uma periodização baseada na troca de paradigmas e insere uma série de conteúdos - como a pré-história americana, etnias indígenas, formação dos estados nacionais, populismo, processos de democratização, ditaduras militares, redemocratização e globalização - que poderiam ser tratados, dentro do ensino de História, nas escolas dos países que participam do Mercosul.

Entretanto, cabe também destacar que há semelhanças entre os temas abordados pelos pesquisadores no decorrer dos seminários. Além do tema da cidadania, discutido por Díaz e Denkberg, as questões da nação e do nacionalismo foram apresentadas por Díaz, Cattáneo e Reichel.

Sobre as demais discussões dos especialistas durante os seminários, podemos sinalizar que elas foram se modificando. Observamos que os temas indicavam a preocupação de que o ensino de História do Mercosul veiculasse abordagens comparativas que possibilitassem a identificação de traços de identidade comuns; que promovessem uma história menos prejudicial ao "outro"; que contemplassem a integração social e o direito à diferença e à conformação de práticas políticas compartilhadas e uma sociedade plural.

Podemos entender, pelas discussões dos especialistas, que há uma necessidade de se pensar o ensino de História no âmbito da formação do bloco regional, mas também no interior de cada país. Para isso, percebe-se que as discussões vislumbram a necessidade de se ampliar as visões restritas do ângulo nacional para o ângulo regional, superando, assim, tanto uma visão eurocêntrica de história como uma visão que denigre o "outro" latino-americano. 
Assim, diante do exposto neste artigo e compreendendo que o Mercosul foi um processo de integração, que se formou pela necessidade de sobrevivência, arriscamos sinalizar que as propostas expostas pelo SEM precisam ser evidenciadas além de seu âmbito administrativo. Uma integração latino-americana, com a pretensão de formar a identidade regional, como objetiva o Mercosul Educacional, necessita colocar em suas metas a formação continuada dos professores, para divulgar, entre os Estados-Partes, o que tem sido produzido da historiografia latino-americana e retomar a realização dos seminários de especialistas - que deixaram de fazer parte do cronograma do SEM - para que seja possível aprofundar o diálogo entre os especialistas do ensino de História e, o que objetiva a direção do Mercosul Educacional, buscar um consenso sobre uma proposta curricular regional que integre o ensino e a pesquisa sobre a América Latina.

\section{Referências}

ARGENTINA. Centro de Información Y Documentación. III Seminario sobre la Enseñanza de la Historia y de la Geografía. Argentina, 2002.

BRASIL. MERCOSUL. Tratado de Assunção. 1991a. Disponível em: <http://www. mercosul.gov.br/tratados-e-protocolos/tratado-de-assuncao-1/>. Acesso em: 30 jan. 2008.

BRASIL. MERCOSUL Educacional. Protocolo de Intenções, 1991b. Disponível em: <http://www.sic.inep.gov.br/en/documents/doc.../203-protocolo-de-intencoes>. Acesso em: 05 dez. 2011.

BRASIL. MERCOSUL Educacional. MERCOSUR/ RME/LI CCR/Ata no 04/04. 2004. Disponível em: <http://www.sic.inep.gov.br>. Acesso em: 10 fev. 2009.

BRASIL. MERCOSUL Educacional. MERCOSUR/ RME/CCR/Ata no 02/07. 2007. Disponível em: < http://www.sic.inep.gov.br>. Acesso em: 21 jul. 2009.

II SEMINÁRIO BIENAL "O ENSINO DE HISTÓRIA E GEOGRAFIA NO CONTEXTO DO MERCOSUL”. Montevidéu-Uruguai, 1999. Disponível em: <http:// unesdoc.unesco.org/images/0012/001231/123129mo.pdf>. Acesso em: 15 ago. 2013.

CITRON, S. Ensinar a História hoje: a memória perdida e reencontrada. Lisboa: Livros Horizonte, 1990.

GADOTTI, M. O Mercosul educacional e os desafios do século XXI. Brasília: MEC/INEP, 2007. Disponível em: <http://www.publicacoes.inep.gov.br>. Acesso em: 12 jul. 2009.

GUIBERNAU. M. Nacionalismos: o Estado nacional e o nacionalismo no século XX. Rio de Janeiro: Jorge Zahar, 1997.

HAGE, J. A. As relações entre a Argentina e o Brasil no Mercosul. 2001. 175 f. Dissertação (Mestrado em Ciência Política) - Universidade Estadual de Campinas, Campinas, 2001.

LEME, Á. A. S. P. A Declaração de Iguaçu (1985): a nova cooperação argentino-brasileira. Porto Alegre: UFRGS, 2006. 
MARFAN, M. A. (Org.). O ensino de História e Geografia no contexto do Mercosul. Brasília: MEC/SEF, 1998.

MARTINS, F. T. Integração sul-americana na segunda metade dos anos 1990: projeto político brasileiro versus assimetrias regionais do subcontinente. História e Multiplicidade: territórios e deslocamentos, São Leopoldo. In: SIMPÓSIO NACIONAL DE HISTÓRIA, 26., 2007, São Leopoldo. Anais... São Leopoldo: UNISINOS, 2007.

MENDONÇA, E. F. A regra do jogo: democracia e patrimonialismo na educação brasileira. Campinas: FE/UNICAMP, 2000.

MOMMA, A. M. As políticas educacionais brasileiras no contexto do Mercosul: perspectivas e desafios para o processo de integração. 2001. 210 f. Dissertação (Mestrado em Educação) - Universidade Estadual de Campinas, Campinas, 2001.

RAIZER, L.; NEVES, C. E. B.; FACHINETTO, R. F. Educação para a Integração: rumo ao Mercosul Educacional?. Empreendorismo, Inovação Tecnológica e Desenvolvimento Regional. In: JORNADA DE JOVENS PESQUISADORES DA AUGM, 14., 2006, Campinas. Anais... Campinas: AUGM, 2006.

REICHEL, H. J. Produção historiográfica no Mercosul: abordagens e tendências. In: MARFAN, M. A. (Org.). O ensino de História e Geografia no contexto do MERCOSUL. Brasília: MEC/SEF, 1998. p. 45-56.

RÜSEN, J. Razão histórica. Brasília: UNB, 2001.

SARAIVA, J. F. S. O Brasil e a integração hemisférica: vertente histórica. Em Aberto, Brasília, v. 15, n. 68, p. 35-44, out./dez. 1995.

SARAIVA, J. F. S. História e Geografia no Mercosul: trajetória e perspectivas. In: MARFAN, M. A. (Org.). O ensino de História e Geografia no contexto do MERCOSUL. Brasília: MEC, SEF, 1998. p. 14-23.

SIMÕES, R. L. Las competencias profesionales para la ensenanza-aprendizaje de las ciencias sociales. In: SIMPOSIO INTERNACIONAL DE DIDACTICA DE LAS CIENCIAS SOCIALES, 18., 2007, Bilbao. Anais... Bilbao: Baster, 2007.

WASSERMAN, C. História: fronteiras/Associação Nacional de História. In: SIMPÓSIO NACIONAL DA ASSOCIAÇÃO NACIONAL DE HISTÓRIA, 20., 1999, São Paulo. Anais... São Paulo: Humanistas/ANPUD, 1999.

Recebido em 28/09/2012

Versão final recebida em 20/05/2013

Aceito em 28/05/2013 